Revista de Derecho

de la Pontificia Universidad Católica de Valparaíso XXIX (Valparaíso, Chile, $2^{\text {do }}$ Semestre de 2007)

[pp. 257 - 266]

\title{
LA APLICACIÓN TEMPORAL DE LA NUEVA REGLA DE CÓMPUTO DEL PLAZO DE PRESCRIPCIÓN DE LA ACCIÓN PENAL EN DELITOS SEXUALES CON VÍCTIMAS MENORES DE EDAD
}

[The Temporary Application of the New Time Bar Calculation Rule of the Prescription of Legal Action Regarding Sexual Offences to Underage Victims]

\author{
Guillermo Oliver Calderón* \\ Pontificia Universidad Católica de Valparaíso
}

\section{RESUMEN}

El nuevo artículo 369 quáter del Código Penal, incorporado por la Ley No 20.207, de 31 de agosto de 2007, ha establecido una nueva regla de cómputo del plazo de prescripción de la acción penal en delitos sexuales con víctimas menores de edad, "congelando" dicho plazo hasta el momento en que éstas alcancen la mayoría de edad. El objetivo de este trabajo es examinar la procedencia o improcedencia de aplicar la citada disposición a hechos realizados antes de su entrada en vigencia. Para ello, el autor niega toda importancia a la naturaleza sustantiva o adjetiva que se atribuya a la prescripción, señalando que lo realmente relevante es analizar si se vería vulnerado el fundamento del principio de irretroactividad penal en caso de aplicarse retroactivamente el mencionado precepto.

Palabras Clave: Prescripción penal - Retroactividad de la ley penal - Irretroactividad de la ley penal - Acción penal - Delitos sexuales - Víctimas - Menores de edad.

\section{Abstract}

New article 369, quarter of the Penal Code, included by Law No. 20.207 of 31 August 2007, has established a new time bar calculation rule of prescription of legal action regarding sexual offences to underage victims by "freezing" said term until they become adults. The aim of this work is to examine whether the application of said disposition to events carried out before they were in force is appropriate or inappropriate. To that end, the author denies the importance to the substantive or adjective nature ascribed to the time bar pointing out that what is really relevant to analyse if the basis of the principle of penal non-retroactivity would be damaged in case that said precept is retroactively applied.

Keywords: Criminal time-bar - Retroactivity of criminal law - Nonretroactivity of criminal law - Criminal action - Sexual Offences - Victims - Minors (underage).

* Profesor de Derecho Penal y Derecho Procesal Penal de la Pontificia Universidad Católica de Valparaíso. Dirección postal: Avda. Brasil 2950, Valparaíso, Chile. Correo electrónico: guillermo.oliver@ucv.cl 


\section{INTRODUCCIÓN}

El día 31 de agosto de 2007 se publicó en el Diario Oficial la Ley No 20.207, que introdujo en el Código Penal un nuevo artículo, el 369 quáter, cuyo tenor es el siguiente: "En los delitos previstos en los dos párrafos anteriores, el plazo de prescripción de la acción penal empezará a correr para el menor de edad que haya sido víctima, al momento que cumpla 18 años".

Es muy probable que esta disposición dé lugar a varias dificultades en su interpretación y aplicación práctica, tales como, entre otras, la de decidir si consagra o no una duplicidad de plazos de prescripción que empezarían a correr en momentos distintos y para personas diferentes; en caso afirmativo, la de precisar las consecuencias que un proceso penal produciría en otro que le sucediera, debido a que distintas personas inicien uno dentro de los diferentes plazos con que contarían para ello, y la de determinar los efectos en el tiempo que produciría la nueva norma. El objetivo de este breve trabajo es contribuir a solucionar sólo uno de tales problemas: el relativo a la posible aplicación retroactiva de esta disposición.

\section{SOBRE LA POSIBILIDAD DE APLICAR LA NUEVA REGLA ESPECIAL DE CÓMPUTO DEL PLAZO DE PRESCRIPCIÓN DE LA ACCIÓN PENAL A DELITOS ANTERIORES A SU ENTRADA EN VIGENCIA}

La prescripción es una de las instituciones que ha originado mayor controversia a la hora de determinar su naturaleza jurídica ${ }^{1}$. Un breve examen de diversas opiniones que sobre este punto se han planteado permite concluir que existen, al menos, tres posiciones disímiles. Por un lado, hay quienes sostienen que se trata de una institución procesal. En este sector destaca Cerezo Mir, quien defiende la naturaleza adjetiva de la prescripción: "por guardar una relación indisoluble con la aplicación del Derecho penal"2. Por otro, algunos afirman que su naturaleza es mixta. Es el caso, verbigracia, de Serrano Butragueño, quien expresa que "la prescripción [...] goza de naturaleza mixta, pues guardando gran relación con los actos del proceso -se interrumpe desde que la acción se dirija contra el culpable [...]-, sin embargo, sus efectos son netamente sustantivos, ya que extingue la responsabilidad penal" ${ }^{3}$. Finalmente, hay quienes, a mi

${ }^{1}$ Sobre el punto, cfr. Ragués I Vallès, Ramon, La prescripción penal. Fundamento y aplicación. Texto adaptado a la LO 15/2003 de reforma del Código Penal (Barcelona, Atelier, 2004), pp. 69 ss.

${ }^{2}$ Cerezo Mir, Curso de Derecho penal español. Parte general (6 edición, Madrid, Tecnos, 2004), I, pp. 224 s.

${ }^{3}$ Serrano Butragueño, Comentario al art. 2, en VV. AA., Código Penal de 
juicio, con razón, afirman que se trata de una figura de naturaleza penal. Así, por ejemplo, Morillas Cueva defiende su naturaleza sustantiva, porque "supone una renuncia por parte del Estado al derecho de castigar basada en razones de política criminal aglutinadas por el transcurrir del tiempo, que incide en que aquél considere extinguida la responsabilidad criminal $y$, por consiguiente, el delito y la pena" ${ }^{\text {". }}$ Pienso que, efectivamente, se trata de una institución penal, dado que es posible advertir en ella una renuncia del Estado para ejercer su potestad penal cuando ha transcurrido un determinado tiempo desde la comisión del delito5.

Traigo a colación las diversas posturas acerca de la naturaleza jurídica de la prescripción, porque algunos autores han planteado que la solución al problema consistente en determinar si la prohibición de aplicar leyes desfavorables ex post facto alcanza o no a las disposiciones relativas a la prescripción (como el art. 369 quáter del Código Penal), depende de cuál sea dicha naturaleza. ${ }^{6}$ Según ellos, si se considera a la prescripción una

1995 (Comentarios y jurisprudencia), coordinados por Ignacio Serrano Butragueño (Granada, Comares, 1998), p. 39.

${ }^{4}$ Morillas Cueva, Derecho Penal. Parte General. Fundamentos conceptuales y metodológicos del Derecho Penal. Ley Penal (Madrid, Dykinson, 2004), pp. 229 ss. Cfr. también El Mismo, Acerca de la prescripción de los delitos y de las penas (Granada, Departamento de Derecho Penal de la Universidad de Granada, 1980), p. 43; Gómez Pavón, La prescripción del delito en el Código Penal, en VV. AA., Estudios de Derecho penal y Criminología. Homenaje al profesor José María Rodríguez Devesa (Madrid, Facultad de Derecho de la Universidad Nacional de Educación a Distancia, 1989), pp. 370 ss., especialmente, p. 373; Mir Puig, Derecho Penal. Parte General (7a edición, Barcelona, Reppertor, 2004), p. 751; Cobo del Rosal - Vives Antón, Derecho Penal. Parte General (5a edición, Valencia, Tirant lo Blanch, 1999), pp. 955 s.; Landecho Velasco - Molina Blázquez, Derecho Penal Español. Parte General (Tecnos, 7ª edición, Madrid, 2004), p. 156; Gallego Díaz, Prescripción penal y prohibición de retroactividad, en Revista General de Legislación y Jurisprudencia, Madrid, enero 1986, p. 37. En la doctrina chilena, véase Cury Urzúa, Derecho Penal. Parte General (7a edición, Santiago, Ediciones Universidad Católica de Chile, 2005), pp. $798 \mathrm{~s}$

${ }^{5}$ En la jurisprudencia española esto ha sido reiteradamente declarado. Véase, por ejemplo, la sentencia del Tribunal Supremo de 19 de diciembre de 1991, ponente Joaquín Delgado García (fundamento jurídico 20). Cfr. Pastor Alcoy, La prescripción en el Código Penal de 1995 y su aplicación retroactiva. Comentarios y formularios (Valencia, Editorial Práctica de Derecho, 1996), p. 86.

${ }^{6}$ Así, Rodríguez Mourullo, Derecho Penal. Parte General (Madrid, Civitas, 1978), p. 139; Ferrer Sama, Comentarios al Código Penal (Murcia, Sucesores de Nogués, 1947), II, pp. $162 \mathrm{s.}$

En Italia la doctrina y la jurisprudencia suelen asignar a esta institución naturaleza penal, de lo que deducen la improcedencia de aplicar retroactivamente los aumentos en los plazos de prescripción. Cfr. Camaioni, Successione di leggi penali (Pa- 
institución penal, la respuesta es afirmativa; si se la estima una figura procesal, en cambio, la respuesta es negativa ${ }^{7}$.

Mi opinión es distinta. Creo que para solucionar el señalado problema lo importante no es determinar cuál es la naturaleza jurídica de la prescripción ${ }^{8}$, sino analizar si la aplicación de una ley sobre prescripción más desfavorable a hechos ocurridos con anterioridad a su entrada en vigencia

dova, Cedam, 2003), pp. 139 ss. Idéntico proceder se observaba en la jurisprudencia francesa anterior a la promulgación del Código Penal de 1992, cuyo art. 112-2 No 4 extiende expresamente la irretroactividad a los aumentos en los plazos de prescripción. Véase Levasseur - Chavanne - Montreuil, Droit pénal général et procédure pénale (10a edición, París, Sirey, 1991), p. 43. Por su parte, la jurisprudencia belga opta por aplicar retroactivamente cualquier modificación, perjudicial o favorable, en las reglas relativas a la prescripción. Cfr. Hennau - Verhaegen, Droit Pénal General (2a edición, Bruselas, Bruylant, 1995), p. 89.

${ }^{7}$ En Alemania, sobre la base de asignar a esta institución naturaleza procesal, se justificó la ampliación retroactiva de los plazos de prescripción de los delitos cometidos por los jerarcas del régimen nazi que aún no habían prescrito. En 1965 se los aumentó para los asesinatos y en 1969 se los volvió a aumentar para los delitos castigados con pena privativa de libertad perpetua, a la vez que se declararon imprescriptibles los delitos de genocidio y las penas impuestas por ellos. Atendido el supuesto carácter adjetivo de la prescripción, se la excluyó de la prohibición de retroactividad penal. Cfr. Gallego Díaz, Prescripción penal, cit., p. 43.; Fletcher, Conceptos básicos de Derecho Penal (traducción y notas de Francisco Muñoz Conde, Valencia, Tirant lo Blanch, 1997), p. 27. Esta posición es todavía dominante en dicho país. Cfr. Roxin, Derecho Penal. Parte General (traducción de la $2^{a}$ edición alemana y notas por Diego Manuel Luzón Peña, Miguel Díaz y García Conlledo y Javier de Vicente Remesal, Civitas, Madrid, 1997), I, p. 165, nota 85.

${ }^{8}$ Cfr., entre otros, Pedreira González, La prescripción de las infracciones penales tras la reforma introducida por la Ley Orgánica 15/2003, de 25 de noviembre, en La Ley, No 6249 (Madrid, martes 10 de mayo de 2005), p. 3; SÁrnz Cantero, Lecciones de Derecho Penal. Parte General (3a edición, Barcelona, Bosch, 1990), p. 396; Ruiz Antón, El principio de irretroactividad de la ley penal en la doctrina y la jurisprudencia, en Poder Judicial, número especial VI (Madrid, 1989): Protección jurisdiccional de los derechos fundamentales y libertades públicas, p. 102; RaGuÉs I VAllès, La prescripción penal, cit., pp. 77 ss.; y FríGOls I BRINES, Fundamentos de la Sucesión de Leyes en el Derecho penal español. Existencia y aplicabilidad temporal de las normas penales (Barcelona, Bosch, 2004), p. 362, quienes restan importancia a la determinación de la naturaleza de la prescripción para decidir si ésta se encuentra o no dentro del radio de acción del principio de irretroactividad y se inclinan por la respuesta afirmativa. En el mismo sentido, en la doctrina alemana, cfr. Freund, Sobre la función legitimadora de la idea de fin en el sistema integral del Derecho penal, en Wolter - Freund (eds.), El sistema integral del Derecho penal. Delito, determinación de la pena y proceso penal (traducción de Ramon Ragués i Vallès, Madrid, Marcial Pons, 2004), pp. 104 s., afirmando que desde una perspectiva material la distinción entre punibilidad y perseguibilidad suena como simple palabrería y oponiéndose a una ampliación retroactiva de los plazos de prescripción. 
vulnera o no el fundamento del principio de irretroactividad en materia penal. Si resulta atacado, entonces debe concluirse que tal aplicación está prohibida. En caso contrario, la prohibición no le afecta. Pienso que esta forma de razonar conduce a extender el ámbito de aplicación de la prohibición de leyes perjudiciales ex post facto a las modificaciones en materia de prescripción. A mi juicio, el basamento de la irretroactividad penal se encuentra en la idea de seguridad jurídica, entendida, en términos negativos, como no exclusión de la posibilidad de los ciudadanos de conocer el ordenamiento jurídico y calcular la calificación jurídico-penal de sus conductas, para evaluar si serán o no castigados y, en caso efectivo, cómo lo serán. Las leyes penales desfavorables no pueden aplicarse retroactivamente, porque si se permitiese hacerlo, las dificultades para conocer el ordenamiento jurídico y anticipar los efectos penales de las actuaciones -que ya son muchas con leyes irretroactivas (por falta de claridad de las leyes, ausencia de prolijidad, complejidad y equivocidad del lenguaje con que se redactan, falta de taxatividad en la descripción de los tipos penales, constantes cambios legales en breves espacios de tiempo, etc.)-se incrementarían hasta alcanzar un nivel inaceptable. De este modo, al establecer la irretroactividad de las leyes penales desfavorables no se busca que los ciudadanos conozcan el derecho -lo que se ha revelado más como un mito que como una realidad-, sino que no sea imposible que lo conozcan -tarea mucho más modesta-, de tal suerte que si efectivamente acceden al mensaje normativo, puedan calcular, con un grado razonable de previsibilidad, la valoración jurídico-penal que de sus actos futuros se haga. Pues bien, si este es el fundamento de la irretroactividad de las leyes penales desfavorables, forzoso es sostener que su radio de acción alcanza a las modificaciones perjudiciales en materia de prescripción, como por ejemplo, las ampliaciones de los plazos de prescripción?. Para que no sea imposible que las personas evalúen los riesgos penales de sus actuaciones y decidan si delinquen o no, es necesario que puedan saber durante cuánto tiempo el Estado puede perseguirlos criminalmente ${ }^{10}$. Como las normas

${ }^{9}$ Cfr., sin embargo, Queralt Jiménez, El principio de legalidad penal (mecanografiado inédito, Barcelona, 1995), pp. 372 ss., quien defiende la procedencia de ampliar los plazos de prescripción en curso, a pesar de sostener que la seguridad jurídica es el fundamento de la exigencia de irretroactividad de las leyes penales.

${ }^{10}$ En contra, cfr. Roxin, Derecho Penal. Parte General, cit., p. 165: "el ciudadano tiene derecho a saber si puede ser castigado y, en su caso, en qué medida, pero el sentido del principio de legalidad no es el de decirle por cuánto tiempo se tendrá que ocultar tras la comisión del hecho, para luego poder reaparecer a salvo". Consecuente con su opinión, este autor no se opone a que las ampliaciones en los plazos de prescripción se apliquen a delitos cometidos antes de su entrada en vigencia, cuando aún no han prescrito, pero - de un modo que me parece un tanto contradictorio con su 
secundarias refuerzan la función motivadora de las normas primarias mediante la amenaza de pena ${ }^{11}$, la consideración del tiempo durante el cual esta amenaza se puede concretar es un importante factor que puede incidir en que los ciudadanos decidan ejecutar o no los hechos a cuya abstención se les pretende motivar ${ }^{12}$. Y la única forma de hacer posible esto es asegurando que las modificaciones desfavorables en las leyes sobre prescripción no se apliquen a hechos anteriores a su entrada en vigencia. De nada sirve que no se excluya la posibilidad de que las personas sepan anticipadamente qué consecuencias jurídico-penales asigna la ley a una determinada clase de conductas, garantizando la irretroactividad de las disposiciones que establecen penas, si no tienen la posibilidad de saber también cómo se llega a la aplicación de esas consecuencias. Un elemento fundamental del camino que conduce a éstas es el inicio del procedimiento penal dentro del plazo de prescripción. En el fondo, si una persona no está en condiciones de prever el cómo de dicho camino -incluyendo las reglas sobre prescripción-, mal puede saber, realmente, el síde la pena. Piénsese en el siguiente caso hipotético. Imaginemos que una persona está evaluando seriamente cometer un delito en un momento en que la legislación establece para el mismo un plazo de prescripción sólo de meses. Es evidente que si a esa persona no se le asegura que, si decide delinquir, eventuales futuras ampliaciones de tal plazo no se le podrán aplicar en su perjuicio, no podrá calcular el si de la pena, frente al abanico de posibilidades susceptibles de representarse: que el plazo se mantenga inalterado -caso en el cual el sujeto contaría con altas expectativas de no resultar sancionado-, que se amplíe o que el delito pase a ser considerado imprescriptible -casos en los cuales las expectativas de ser castigado aumentarían de manera considerable-.

Lo que he dicho me parece plenamente aplicable al nuevo art. 369 quáter del Código Penal. En el fondo, lo que ha hecho el legislador al establecer que en los casos que la disposición menciona el plazo de prescripción empieza a correr cuando la víctima llega a la mayoría de edad es, materialmente, una ampliación indeterminada de los plazos de prescrip-

planteamiento- rechaza que tales ampliaciones se apliquen a delitos ejecutados antes de su entrada en vigor que ya han prescrito.

${ }^{11}$ Cfr. Mir Puig, Derecho Penal. Parte General, cit., p. 80; Silva Sánchez, Aproximación al Derecho penal contemporáneo (Barcelona, Bosch, 1992), pp. $355 \mathrm{~s}$.

${ }^{12}$ Así, Levasseur, Opinions heterodoxes sur les conflits de lois repressives dans le temps, en VV.AA., En Hommage a Jean Constant (Liège, Faculté de Droit de Liège, 1971), p. 220; ThÉodosiadès, Essai sur la non-rétroactivité des lois (París, Ed. Abel Pilon, 1866), p. 223. En contra, Queralt Jiménez, El principio de legalidad penal, cit., p. 371, quien sostiene que es "insusceptible cualquier sujeto de ser motivado mediante la prescripción”. 
ción. Digo indeterminada, porque para precisar el tiempo en que se ve aumentado el plazo de prescripción de la acción penal de un delito sexual contra un menor de edad, será necesario saber la edad de la víctima. Si ésta tuviera 17 ańos de edad, el incremento del plazo sería de un año, que será lo que le reste para alcanzar la mayoría de edad, evento en que comenzaría recién a correr el plazo que corresponda conforme a las reglas generales; si tuviera 4 ańos de edad, el aumento sería de 14 años. En otras palabras, el legislador ha aumentado los plazos de prescripción de la acción penal en delitos sexuales contra menores de edad en tanto tiempo cuanto le falte a la víctima para llegar a la mayoría de edad. Y como se trata de un aumento -indeterminado- de plazos de prescripción, entonces es forzoso concluir que no puede aplicarse retroactivamente a hechos anteriores a su entrada en vigencia. El sentido de garantía de la prohibición de aplicar leyes más severas ex post facto, que asegura a las personas que no serán perjudicadas en sus expectativas de no ser sancionadas -o no serlo tanto-, generadas por la legislación vigente al tiempo de la ejecución del hecho, se vería seriamente afectado, si no se extendiera a los cambios en la legislación que facilitan el castigo del mismo ${ }^{13}$. Es obvio que con el aumento del plazo de prescripción de delitos sexuales contra menores de edad que prevé el nuevo art. 369 quáter del Código Penal, se facilitaría el castigo de los hechos cometidos con anterioridad a su entrada en vigor, si se lo pretendiera aplicar a éstos ${ }^{14}$.

La mejor demostración de que ninguna importancia debería tener en Chile la discusión acerca de la naturaleza de la prescripción para solucionar el problema planteado, la proporcionan los artículos 18 del Código Penaly 11 del Código Procesal Penal. Si se asignara naturaleza penal a la prescripción, el primer precepto citado serviría para reconocer la irretroactividad del nuevo art. 369 quáter del Código Penal. Si se afirmara que se trata de una institución procesal, el segundo precepto citado permitiría arribar a idéntica conclusión ${ }^{15}$. Es cierto que, en estricto rigor, al establecer la irretroactividad penal, el art. 18 inc. $1^{\circ}$ del Código Penaly el art. 19 No 3

${ }^{13}$ Cfr. Mir Puig, Sobre la irretroactividad de las normas procesales y el sujeto del delito de bigamia, en La Ley, 3 (Madrid, 1986), pp. $260 \mathrm{s.}$

${ }^{14}$ Véase. también Pastor, Acerca de presupuestos e impedimentos procesales y sus tendencias actuales, en VV. AA., Nuevas formulaciones en las ciencias penales. Homenaje a Claus Roxin (Córdoba, Argentina, Marcos Lerner Editora Córdoba - La Lectura Libros Jurídicos, 2001), pp. 807 s., cuyo planteamiento conduce a sostener que las normas procesales integran la norma penal secundaria, tesis que, si se asignara naturaleza adjetiva a la prescripción, podría servir para apoyar mi opinión.

${ }^{15}$ Cfr. Politoff Lifschitz - Matus Acuña - Ramírez Guzmán, Lecciones de Derecho Penal Chileno. Parte General ( $1^{\text {a }}$ edición, Santiago, Editorial Jurídica de Chile, 2004), p. 128, nota 68. 
inc. $7^{\circ}$ de la Constitución Politica de la República aluden a las leyes que establecen las penas aplicables y no a aquellas que se refieren a la prescripción (plazos, manera de computarlos, forma de suspenderlos e interrumpirlos, etc.). Pero es evidente que estas disposiciones se fundan en el necesario respeto de la seguridad jurídica y ya he explicado cómo se vulneraría ésta si se dejaran fuera del radio de acción del principio de irretroactividad de las leyes penales desfavorables las modificaciones perjudiciales en materia de prescripción.

Como otro argumento para apoyar mi opinión puede invocarse lo que la doctrina y la jurisprudencia ibéricas han sostenido a propósito del art. 132.1 del Código Penal español de 1995, similar al art. 369 quáter del Código Penal chileno, y que fue uno de los antecedentes que se tuvieron a la vista durante la tramitación parlamentaria de la Ley No $20.207^{16}$. Esta disposición fue modificada en España por la Ley Orgánica 11/1999, de 30 de abril y luego vuelta a cambiar por la Ley Orgánica 14/1999, de 9 de junio. Estas modificaciones buscaban "congelar" el inicio de los plazos de prescripción cuando la víctima en ciertos delitos ("tentativa de homicidio, delitos de aborto no consentido, lesiones, contra la libertad, de torturas y contra la integridad moral, la libertad e indemnidad sexuales, la intimidad, el derecho a la propia imagen y la inviolabilidad del domicilio") fuera menor de edad, hasta que alcanzara la mayoría de edad. Conforme a la doctrina española, estas modificaciones no pueden ser aplicadas en el cómputo de los plazos de prescripción de los delitos cometidos antes de su incorporación en el Código Penal. De lo contrario, se burlaría la seguridad jurídica ${ }^{17}$. El Tribunal Supremo español así también lo ha entendido ${ }^{18}$. No veo razón alguna para que la jurisprudencia chilena sostenga algo distinto para la nueva regla especial de cómputo del plazo de prescripción prevista en el art. 369 quáter del Código Penal.

\section{CONCLUSIONES}

Como conclusiones de este trabajo pueden formularse las siguientes:

a) Para determinar si el radio de acción del principio de irretroactividad

${ }^{16}$ Véase el Informe de la Comisión de Constitución, Legislación y Justicia de la Cámara de Diputados de fecha 15 de junio de 2005 (Boletines 3786-07 y 3799-07, refundidos).

${ }^{17}$ Así, RaguÉs I VALLÈs, La prescripción penal, cit., pp. 150 ss., especialmente p. 154.

${ }^{18}$ En este sentido pueden verse sus sentencias de 15 de abril de 2005, ponente Perfecto Andrés Ibáńez (fundamento jurídico 5º y de 11 de febrero de 2003, ponente Julián Sánchez Melgar (fundamento jurídico 3º). 
de las leyes penales desfavorables alcanza a las modificaciones perjudiciales en materia de prescripción lo importante no es decidir que se trata de una institución penal o de una procesal, sino analizar si su aplicación retroactiva vulneraría o no el fundamento de dicho principio, es decir, la seguridad jurídica.

b) La seguridad jurídica se vería afectada si tuviera lugar una aplicación retroactiva de una modificación desfavorable en materia de prescripción, como por ejemplo, un aumento en el plazo de prescripción de la acción penal para perseguir un delito, por lo que debe estimarse que el principio de irretroactividad penal cubre estas situaciones.

c) El nuevo art. 369 quáter del Código Penal contiene, materialmente, una ampliación indeterminada de los plazos de prescripción de ciertos delitos sexuales contra víctimas menores de edad, por lo que sólo puede aplicarse a hechos que tengan lugar después de su entrada en vigencia.

[Recibido el 23 y aceptado el 31 de octubre de 2007].

\section{BIBLIOGRAFÍA}

Camaioni, Salvatore, Successione di leggi penali (Padova, Cedam, 2003).

Cerezo Mir, José, Curso de Derecho penal español. Parte general (6a edición, Madrid, Tecnos, 2004), I.

Cobo del Rosal, Manuel - Vives Antón, Tomás Salvador, Derecho Penal. Parte General (5 edición, Valencia, Tirant lo Blanch, 1999).

Cury Urzúa, Enrique, Derecho Penal. Parte General (7a edición, Santiago, Ediciones Universidad Católica de Chile, 2005).

Ferrer Sama, Antonio, Comentarios al Código Penal (Murcia, Sucesores de Nogués, 1947), II.

Fletcher, George, Conceptos básicos de Derecho Penal (traducción y notas de Francisco Muñoz Conde, Valencia, Tirant lo Blanch, 1997).

Freund, Georg, Sobre la función legitimadora de la idea de fin en el sistema integral del Derecho penal, en Wolter, Jürgen - Freund, Georg (eds.), El sistema integral del Derecho penal. Delito, determinación de la pena y proceso penal (traducción de Ramon Ragués i Vallès, Madrid, Marcial Pons, 2004), pp. 91-128.

Frígols I Brines, Eliseu, Fundamentos de la sucesión de leyes en el Derecho penal español. Existencia y aplicabilidad temporal de las normas penales (Barcelona, Bosch, 2004).

Gallego Díaz, Manuel, Prescripción penal y prohibición de retroactividad, en Revista General de Legislación y Jurisprudencia (Madrid, enero 1986), pp. 27-48.

Gómez Pavón, Pilar, La prescripción del delito en el Código Penal, en VV. AA., Estudios de Derecho penal y Criminología. Homenaje al profesor José María Rodríguez Devesa (Madrid, Facultad de Derecho de la Universidad Nacional de Educación a Distancia, 1989), I, pp. 369-391.

Hennau, Christiane - Verhaegen, Jacques, Droit Pénal General (2a edición, Bruselas, Bruylant, 1995). 
Landecho Velasco, Carlos María - Molina Blázquez, Concepción, Derecho Penal Español. Parte General (7a edición, Madrid, Tecnos, 2004).

Levasseur, Georges - Chavanne, Albert - Montreuil, Jean, Droit pénal général et procédure pénale (10a edición, París, Sirey, 1991).

Levasseur, Georges, Opinions heterodoxes sur les conflits de lois repressives dans le temps, en VV.AA., Hommage a Jean Constant (Liège, Faculté de Droit de Liège, 1971), pp. 189-254.

Mir Puig, Santiago, Derecho Penal. Parte General (7a edición, Barcelona, Reppertor, 2004).

Mir Puig, Santiago, Sobre la irretroactividad de las normas procesales y el sujeto del delito de bigamia, en La Ley (Madrid, 1986) 3, pp. 259-264.

Morillas Cueva, Lorenzo, Acerca de la prescripción de los delitos y de las penas (Granada, Departamento de Derecho Penal de la Universidad de Granada, 1980).

Morillas Cueva, Lorenzo, Derecho Penal. Parte General. Fundamentos conceptuales y metodológicos del Derecho Penal. Ley Penal (Madrid, Dykinson, 2004).

Pastor Alcoy, Francisco, La prescripción en el Código Penal de 1995 y su aplicación retroactiva. Comentarios y formularios (Valencia, Editorial Práctica de Derecho, 1996).

Pastor, Daniel R., Acerca de presupuestos e impedimentos procesales y sus tendencias actuales, en VV. AA., Nuevas formulaciones en las Ciencias penales. Homenaje a Claus Roxin (Córdoba, Argentina, Marcos Lerner Editora Córdoba - La Lectura Libros Jurídicos, 2001), pp. 793-822.

Pedreira González, Félix, La prescripción de las infracciones penales tras la reforma introducida por la Ley Orgánica 15/2003, de 25 de noviembre, en La Ley, № 6249 (Madrid, martes 10 de mayo de 2005), pp. 1-10.

Politoff Lifschitz, Sergio - Matus Acuña, Jean Pierre - Ramírez Guzmán, María Cecilia, Lecciones de Derecho Penal Chileno. Parte General ( $1^{\text {a }}$ edición, Santiago, Editorial Jurídica de Chile, 2004).

Queralt JimÉnez, Joan Josep, El principio de legalidad penal (mecanografiado inédito, Barcelona, 1995), 448 páginas.

Ragués I VAlLÈs, Ramon, La prescripción penal, Fundamento y aplicación. Texto adaptado a la LO 15/2003 de reforma del Código Penal (Barcelona, Atelier, 2004).

Rodríguez Mourullo, Gonzalo, Derecho Penal. Parte General (Madrid, Civitas, 1978).

Roxin, Claus, Derecho Penal. Parte General (traducción de la 2a edición alemana y notas por Diego-Manuel Luzón Peña, Miguel Díaz y García Conlledo y Javier de Vicente Remesal, Madrid, Civitas, 1997), I.

Ruiz Antón, Luis Felipe, El principio de irretroactividad de la ley penal en la doctrina y la jurisprudencia, en Poder Judicial, número especial vi (Madrid, 1989): Protección jurisdiccional de los derechos fundamentales y libertades públicas, pp. 95-107.

Sáinz Cantero, José A., Lecciones de Derecho Penal. Parte General (3a edición, Barcelona, Bosch, 1990).

Serrano Butragueño, Ignacio, Comentario al art. 2, en VV. AA., Código Penal de 1995 (Comentarios y jurisprudencia), coordinados por Ignacio Serrano Butragueño (Granada, Comares, 1998), pp. 28-43.

Silva SÁnchez, Jesús María, Aproximación al Derecho penal contemporáneo (Barcelona, Bosch, 1992).

Théodosiadès, Miltiade C., Essai sur la non-rétroactivité des lois (París, Ed. Abel Pilon, 1866). 